\title{
Effect of Asthmatic Acute Phase on Theophylline Clearance in Japanese Pediatric Patients during Constant Aminophylline Infusion
}

\author{
Tsutomu Igarashi ${ }^{* 1}$ and Seigo Iwakawa ${ }^{2}$ \\ Department of Pharmacy, Itami City Hospital ${ }^{1}$ and \\ Department of Pharmaceutics, Kobe Pharmaceutical University ${ }^{2}$ \\ $\left[\begin{array}{l}\text { Received January 26, } 2010 \\ \text { Accepted A pril 26, } 2010\end{array}\right]$
}

The changes in theophylline clearance in 115 Japanese pediatric patients ( 72 males and 43 females) aged from 0.5 to 4 years undergoing a constant rate aminophylline infusion were investigated during the asthmatic acute phase. Plasma theophylline concentration data, which were retrospectively obtained from routine therapeutic drug monitoring, were divided into 2 groups according to the time from initiation of aminophylline infusion (up to 48 hours or more than 60 hours) in order to estimate theophylline clearance.

In male patients, the theophylline clearance estimated for more than 60 hours was $27 \%$ higher than that for up to 48 hours $(p<0.01)$ for ages $2-<5$ years. In female patients, the theophylline clearance estimated for more than 60 hours was $35 \%$ higher than that for up to 48 hours $(p<0.05)$ for ages $2-<5$ years.

Our findings suggested that the theophylline clearance estimated for more than 60 hours from the initiation of a constant aminophylline infusion could not be safely used in setting the next initial dose of aminophylline in the asthmatic acute phase in pediatric patients.

Key words — theophylline, therapeutic drug monitoring, pharmacokinetics, clearance, infusion time, children

\section{Introduction}

Intravenous infusion of aminophylline during the asthmatic acute phase is used to treat pediatric patients ${ }^{1-3)}$. The therapeutic and toxic effects of theophylline are related to the plasma levels of this drug, and the clearance of theophylline is the determinant parameter of the dosing rate re quired to produce therapeutic plasma levels ${ }^{4-6}$. However, theophylline clearance varies with numerous factors such as age, gender, concurrent drugs, and complicating diseases ${ }_{4,6-8)}$. It has been reported that considerable changes in theophylline clearance can occur in children with acute asthma within a few days (at least 72 hours) of the initiation of a constant aminophylline infusion ${ }^{9}$.

Kubo et al . 9) estimated the theophylline clearances of 13 children from their plasma theophylline levels at 24,48 , and 72 hours after the initiation of a constant aminophylline infusion and demonstrated that theophylline clearance increases with infusion time, even when the intravenous infusion rate of aminophylline is kept constant. However, the subjects in their study ${ }^{9}$ were almost all male (12 of 13 children) and there were no children under 4 years old. There fore, it is unclear whether clinically significant changes in theophylline clearance occur in females and/or children under 4 years old receiving aminophylline infusions. The available data concerning theophylline clearance accompanied by records of the duration of constant aminophylline infusion are limited, particularly in infants who should receive careful dosing of theophylline according to the Japanese guidelines for pediatric asthma ${ }^{10)}$.

The aim of this report is to investigate quantitatively whether theophylline clearance increases with the period of constant aminophylline infusion in male and female children under 5 years old.

\section{Methods}

\section{Patients}

We retrospectively investigated the theophylline clearances of 115 Japanese pediatric patients in the asthmatic acute phase ( 72 males and 43 females) ranging in age from 0.5 to 4 years and in weight from 6.3 to $18.2 \mathrm{~kg}$. A ll patients were admitted as emergency cases to Itami City Hospital be cause of acute airway obstruction and received intravenous constant-rate infusions of aminophylline (Neophylline, Eisai, Co. Ltd.). The data from pediatric patients in the asthmatic acute phase were retrospectively collected from the routine 
clinical records. This study covered the period from January 2001 to December 2004, when theophylline was commonly used, and was approved by the Ethics Committee of Itami City Hospital. Before admission, most patients had received a few inhalations of salbutamol and an intravenous loading bolus of aminophylline. After admission, aminophylline mixed with transfusion fluids ( $\mathrm{Na} 35 \mathrm{mEq} / \mathrm{L}, \mathrm{K} 20 \mathrm{mEq} / \mathrm{L}$, $\mathrm{Cl} 35 \mathrm{mEq} / \mathrm{L}$, lactate $20 \mathrm{mEq} / \mathrm{L}$, and glucose $4.3 \%$ ) was given using an STC-508 constant infusion pump (Terumo, Co. Ltd.). These patients received additional medication such as antibiotics, systemic steroids, salbutamol inhalations, oxygen supply, and anti-tussives as determined by pediatricians. No subjects showed serious airway disorders such as respiratory failure. The demographic and medication data of the male and female pediatric patients are shown in Tables $\mathbf{1}$ and $\mathbf{2}$, respectively.

The data of each patient were collected by reviewing medical records, which included medical history, clinical progress, laboratory data, body temperature, concurrent drugs, and the time records of the administrated drugs. The criteria for selection were the data on the patients who had correctly received a constant-rate intravenous infusion of aminophylline and then had their steady state theophylline concentration measured. The data from patients were excluded (1) if the patient was diagnosed with hepatic dys function, renal dysfunction, congestive heart failure, or congenital disease; (2) if the patient had a fever, based on the report of Toba et al ${ }^{11)}$, with a body temperature of more than $38^{\circ} \mathrm{C}$ twice or more during an interval of 3 hours or with a body temperature of more than $38^{\circ} \mathrm{C}$ and a $\mathrm{C}$-reactive protein concentration of more than $0.5 \mathrm{mg} / \mathrm{dl}$ within 24 hours before sampling; (3) if the patient was concurrently receiving drugs regarded to affect theophylline clearance such as erythromycin, clarithromycin, or phenobarbital ; and (4) if the patient had received oral theophylline within 24 hours before the estimation of theophylline clearance.

The two patient groups according to the infusion period in this study were studied according to the report of Kubo et al. 9) who demonstrated that theophylline clearance at 72 hours significantly increased than that at 48 hours after the

Table 1 . Demographic and medication data of male pediatric patients of different ages and with different infusion times.

\begin{tabular}{|c|c|c|c|c|c|c|}
\hline \multirow{2}{*}{$\begin{array}{l}\text { Age Group (years) } \\
\text { Infusion time after start of aminophylline }\end{array}$} & \multicolumn{2}{|c|}{$0.5-<2$} & \multicolumn{2}{|c|}{$2-<5$} & \multicolumn{2}{|c|}{ Total } \\
\hline & Within $48 \mathrm{~h}$ & More than $60 \mathrm{~h}$ & Within $48 \mathrm{~h}$ & More than $60 \mathrm{~h}$ & Within $48 \mathrm{~h}$ & More than $60 \mathrm{~h}$ \\
\hline Number of patients & 28 & 22 & 30 & 14 & 55 & 34 \\
\hline (with 1 measurement) & 25 & 17 & 26 & 12 & 45 & 25 \\
\hline (with 2 measurements) & 3 & 2 & 4 & & 10 & 4 \\
\hline (with 3 measurements) & & 1 & & 2 & & 3 \\
\hline (with >3 measurements) & & 2 & & & & 2 \\
\hline Total number of measurements & 31 & 32 & 34 & 18 & 65 & 50 \\
\hline Age (years) $\left.{ }^{a}\right)$ & $1.1 \pm 0.5$ & $1.3 \pm 0.4$ & $3.3 \pm 0.9$ & $3.3 \pm 0.9$ & $2.3 \pm 1.3$ & $2.1 \pm 1.2$ \\
\hline Weight $\left.(\mathrm{kg})^{a}\right)$ & $9.4 \pm 1.8$ & $9.6 \pm 1.4$ & $14.2 \pm 2.5$ & $14.3 \pm 2.7$ & $11.9 \pm 3.2$ & $11.5 \pm 3.1$ \\
\hline Duration of hospital stays $(\mathrm{d})^{a)}$ & $7.9 \pm 3.3$ & $7.7 \pm 2.9$ & $6.5 \pm 1.8$ & $7.3 \pm 1.9$ & $7.2 \pm 2.8$ & $7.6 \pm 2.6$ \\
\hline Infusion rate of theophylline $(\mathrm{mg} / \mathrm{h} / \mathrm{kg})^{a)}$ & $0.46 \pm 0.10$ & $0.48 \pm 0.08$ & $0.59 \pm 0.08$ & $0.58 \pm 0.10$ & $0.53 \pm 0.11$ & $0.52 \pm 0.10$ \\
\hline Sampling time after start of infusion $(h)^{a)}$ & $31.5 \pm 10.4$ & $88.7 \pm 34.3$ & $25.6 \pm 8.9$ & $90.4 \pm 31.7$ & $28.7 \pm 9.8$ & $89.4 \pm 33.1$ \\
\hline Concentration of theophylline $(\mu \mathrm{g} / \mathrm{ml})^{a)}$ & $8.6 \pm 2.3$ & $8.6 \pm 2.7$ & $10.3 \pm 2.8$ & $7.9 \pm 2.4$ & $9.6 \pm 2.6$ & $8.3 \pm 2.5$ \\
\hline Concentration range of theophylline $\left.(\mu \mathrm{g} / \mathrm{ml})^{a}\right)$ & $4.9-15.7$ & $4.5-14.3$ & $3.3-15.0$ & $4.5-14.3$ & $3.3-15.7$ & $4.5-14.3$ \\
\hline \multicolumn{7}{|l|}{ Loading bolus dose of theophylline $\left.(\mathrm{mg} / \mathrm{kg})^{b}\right)$} \\
\hline $5-<6$ & & 1 & 3 & 1 & 3 & 2 \\
\hline $4-<5$ & 4 & 2 & 4 & 1 & 8 & 3 \\
\hline $3-<4$ & 5 & 4 & 7 & 8 & 12 & 12 \\
\hline $2-<3$ & 17 & 16 & 14 & 5 & 31 & 21 \\
\hline $1-<2$ & & & 2 & & 2 & \\
\hline no dose & 5 & 9 & 4 & 3 & 9 & 12 \\
\hline \multicolumn{7}{|l|}{ Concurrently used drugs ${ }^{c}$ ) } \\
\hline Antibiotics (intravenous) ${ }^{d}$ ) & 27 & 23 & 22 & 13 & 49 & 36 \\
\hline Prednisolone (intravenous) & 4 & 4 & 12 & 1 & 16 & 5 \\
\hline Oxygen supply ${ }^{e}$ & 1 & 1 & 9 & 1 & 10 & 2 \\
\hline Salbutamol (inhalation) & 31 & 32 & 33 & 17 & 64 & 49 \\
\hline Terbutaline (oral) & 24 & 26 & 23 & 11 & 47 & 37 \\
\hline
\end{tabular}

a) Data represent the mean \pm S.D.

$b$ ) Data represent the number of cases. Loading bolus doses were determined by pediatricians according to the serum level of theophylline and/or the compliance of oral theophylline before the bolus.

c) Data represent the number of cases concurrently using the indicated drugs.

d) Cefotiam dihydrochloride and clindmycin phosphate were the most frequently used antibiotics.

e) Oxygen was supplied via face mask or nasal cannula. 
Table 2 . Demographic and medication data of female pediatric patients of different ages and with different infusion times.

\begin{tabular}{|c|c|c|c|c|c|c|}
\hline \multirow{2}{*}{$\begin{array}{l}\text { Age Group (years) } \\
\text { Infusion time after start of aminophylline }\end{array}$} & \multicolumn{2}{|c|}{$0.5-<2$} & \multicolumn{2}{|c|}{$2-<5$} & \multicolumn{2}{|c|}{ Total } \\
\hline & Within $48 \mathrm{~h}$ & More than $60 \mathrm{~h}$ & Within $48 \mathrm{~h}$ & More than $60 \mathrm{~h}$ & Within $48 \mathrm{~h}$ & More than $60 \mathrm{~h}$ \\
\hline Number of patients & 10 & 14 & 17 & 10 & 27 & 23 \\
\hline (with 1 measurement) & 10 & 13 & 14 & 10 & 24 & 21 \\
\hline (with 2 measurements) & & 1 & 3 & & 3 & 2 \\
\hline \multicolumn{7}{|l|}{ (with 3 measurements) } \\
\hline \multicolumn{7}{|l|}{ (with $>3$ measurements) } \\
\hline Total number of measurements & 10 & 15 & 20 & 10 & 30 & 25 \\
\hline Age $(\text { years })^{a)}$ & $1.2 \pm 0.4$ & $1.4 \pm 0.3$ & $3.4 \pm 0.8$ & $3.3 \pm 0.9$ & $2.6 \pm 1.3$ & $2.2 \pm 1.2$ \\
\hline Weight $(\mathrm{kg})^{a)}$ & $9.7 \pm 1.8$ & $9.9 \pm 1.5$ & $14.0 \pm 1.3$ & $14.0 \pm 1.2$ & $12.4 \pm 2.6$ & $11.6 \pm 2.5$ \\
\hline Duration of hospital stays $\left.(\mathrm{d})^{a}\right)$ & $7.6 \pm 2.8$ & $7.3 \pm 1.9$ & $6.4 \pm 2.5$ & $7.7 \pm 2.1$ & $6.9 \pm 2.6$ & $7.5 \pm 1.9$ \\
\hline Infusion rate of theophylline $(\mathrm{mg} / \mathrm{h} / \mathrm{kg})^{a)}$ & $0.48 \pm 0.07$ & $0.45 \pm 0.09$ & $0.57 \pm 0.08$ & $0.50 \pm 0.10$ & $0.54 \pm 0.09$ & $0.47 \pm 0.10$ \\
\hline Sampling time after start of infusion $\left.(\mathrm{h})^{a}\right)$ & $33.1 \pm 10.5$ & $82.5 \pm 19.5$ & $26.4 \pm 8.5$ & $97.4 \pm 33.3$ & $28.9 \pm 9.6$ & $87.9 \pm 26.6$ \\
\hline Concentration of theophylline $(\mu \mathrm{g} / \mathrm{ml})^{a t}$ & $10.2 \pm 2.4$ & $8.4 \pm 2.3$ & $11.3 \pm 2.3$ & $7.6 \pm 2.2$ & $10.9 \pm 2.3$ & $8.0 \pm 2.2$ \\
\hline Concentration range of theophylline $(\mu \mathrm{g} / \mathrm{m} 1)^{a)}$ & $5.8-12.9$ & $4.9-12.2$ & $6.6-14.8$ & $3.5-10.5$ & $5.8-14.8$ & $3.5-12.2$ \\
\hline \multicolumn{7}{|l|}{ Loading bolus dose of theophylline $\left.(\mathrm{mg} / \mathrm{kg})^{b}\right)$} \\
\hline \multicolumn{7}{|l|}{$5-<6$} \\
\hline $4-<5$ & & & 2 & 2 & 2 & 2 \\
\hline $3-<4$ & 2 & 4 & 5 & 1 & 7 & 5 \\
\hline $2-<3$ & 7 & 7 & 9 & 5 & 16 & 12 \\
\hline $1-<2$ & & & 2 & 1 & 2 & 1 \\
\hline no dose & 1 & 4 & 2 & 1 & 3 & 5 \\
\hline \multicolumn{7}{|l|}{ Concurrently used drugs ${ }^{c}$ ) } \\
\hline Antibiotics (intravenous) ${ }^{d)}$ & 9 & 15 & 15 & 9 & 24 & 24 \\
\hline Prednisolone (intravenous) & 2 & 0 & 10 & 1 & 12 & 1 \\
\hline Oxygen supply ${ }^{e}$ ) & 2 & 1 & 4 & 1 & 6 & 2 \\
\hline Salbutamol (inhalation) & 10 & 15 & 20 & 10 & 30 & 25 \\
\hline Terbutaline (oral) & 5 & 12 & 15 & 9 & 20 & 21 \\
\hline
\end{tabular}

a) Data represent the mean \pm S.D.

b) Data represent the number of cases. Loading bolus doses were determined by pediatricians according to the serum level of theophylline and/or the compliance of oral theophylline before the bolus.

$c$ ) Data represent the number of cases concurrently using the indicated drugs.

d) Cefotiam dihydrochloride and clindmycin phosphate were the most frequently used antibiotics.

e) Oxygen was supplied via face mask or nasal cannula.

initiation of a constant aminophylline infusion. One group consisted of theophylline clearances estimated within 48 hours after the initiation of constant aminophylline infusion, and another group consisted of theophylline clearances estimated at more than 60 hours after the initiation of constant aminophylline infusion.

\section{Estimation of theophylline clearance}

The theophylline clearance $(\mathrm{mL} / \mathrm{h} / \mathrm{kg})$ of each patient was calculated using the following formula: clearance $=10^{3}$ $\times R / C s s$, where $R$ is the constant infusion rate of the dose of theophylline $(\mathrm{mg} / \mathrm{h} / \mathrm{kg})$, and Css is the steady state concentration of theophylline $(\mu \mathrm{g} / \mathrm{mL})$. The steady state concentration is usually achieved after four half-lives following the initiation of a constant-rate infusion ${ }^{12)}$. Since the elimina tion half-life of theophylline is approximately 4 hours for pediatric patients, the steady state concentration was assessed at more than 16 hours after the initiation of constant-rate infusion of aminophylline ${ }^{13)}$. Most patients at admission were recognized as already approaching the steady state because of the previously administered loading bolus dose of aminophylline.

The serum concentrations of theophylline were determined by a fluorescence polarization immunoassay (FPIA, TDX theophylline assay system, Abbott Laboratories). The detection range of theophylline was from 0.82 to $4 \mathrm{q} \mathrm{g} / \mathrm{mL}^{14)}$.

\section{Comparison and statistical analysis}

The theophylline clearances estimated within 48 hours and at more than 60 hours after the initiation of constant aminophylline infusion were compared in the same gender and age group patients, at ages $0.5-<2$ and $2-<5$ years. If the theophylline clearance was calculated more than once for a patient, the clearance was averaged for the patient. The sta tistical analysis was performed using Statcel 2 software, which was installed as an add-on to Microsoft Excel. Evaluation of the significance of the differences in theophylline clearance was performed with the unpaired Student's $t$-test or Welch's $t$-test using a two-side test. The demographic characteristics of the patients were analyzed by the chi- 
squared test or the unpaired t-test as appropriate. In addition, for the purpose of investigating intra patient variability, the ophylline clearances estimated within 48 hours and at more than 60 hours in the same patients were compared using the paired $t$-test if these paired theophylline clearances were es timated consecutively after a constant-rate aminophylline infusion.

\section{Results}

The theophylline clearances of pediatric patients estimated within 48 hours and at more than 60 hours after the initiation of constant aminophylline infusion are shown in Fig. 1. In the male patients, the theophylline clearances estimated within 48 hours and at more than 60 hours were $56.2+15.4$

Male Patients

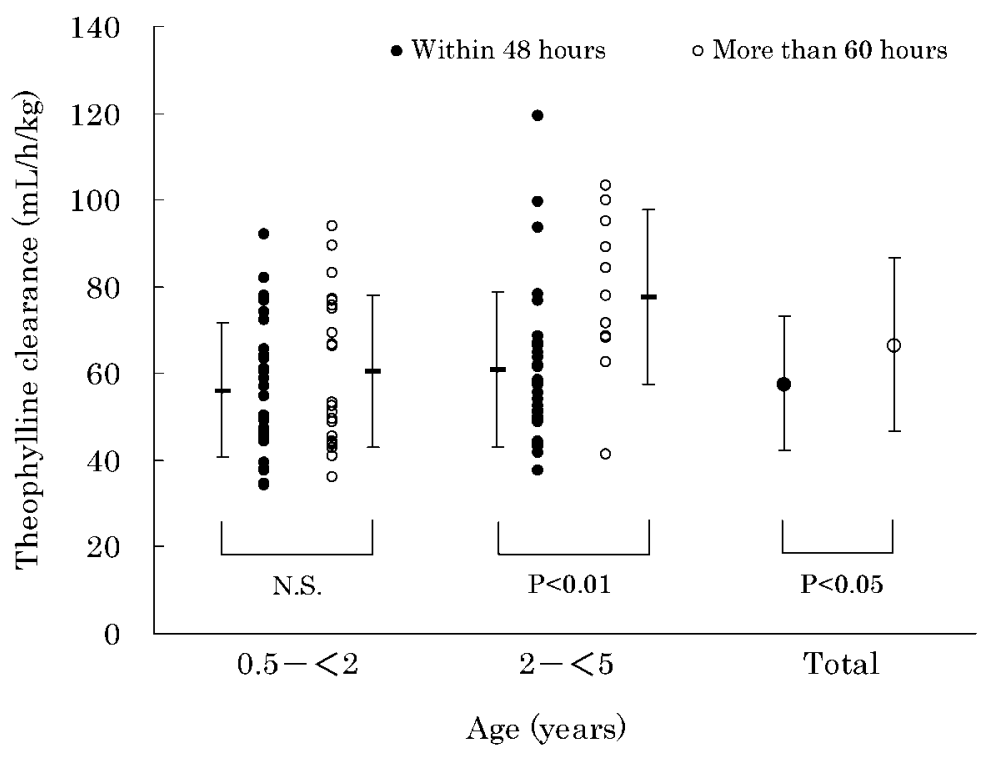

Female Patients

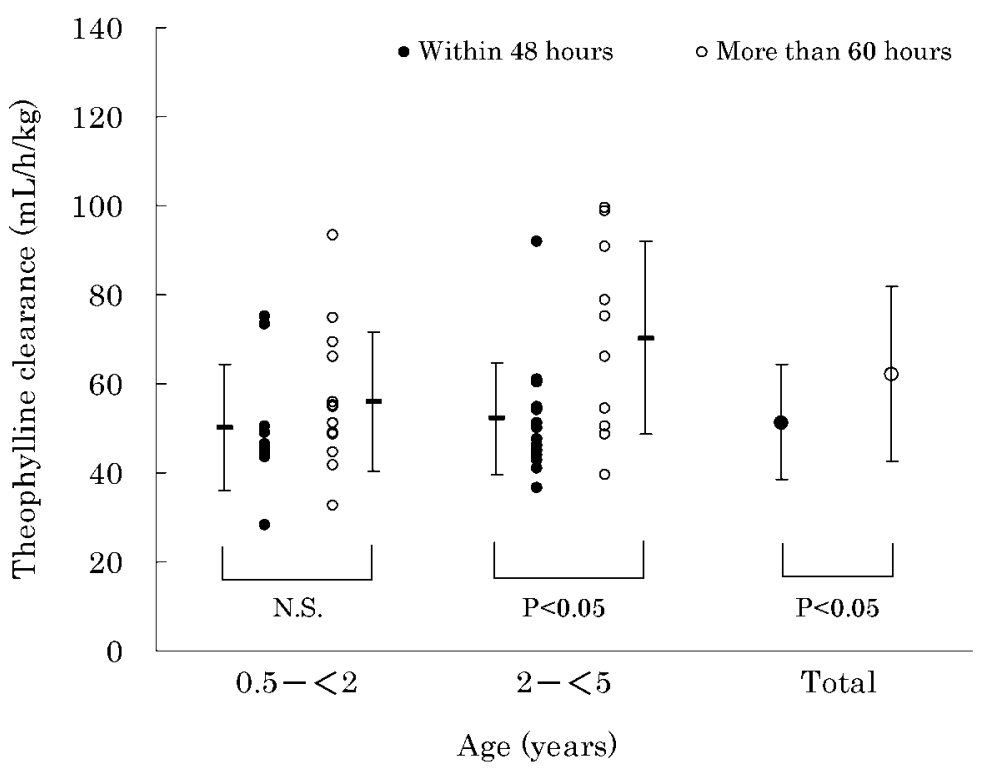

Fig 1. Effect of the asthmatic acute phase on theophylline clearance in male and female pediatric patients during constant infusion of aminophylline.

Each symbol represents the value of theophylline clearance for each patient. Bars represent the mean \pm S.D. , within 48 hours (theophylline clearance estimated within 48 hours after the initia tion of aminophylline infusion) ; $\bigcirc$, more than 60 hours (theophylline clearance estimated at more than 60 hours after the initiation of aminophylline infusion). 
and $60.4 \pm 17.5 \mathrm{~mL} / \mathrm{h} / \mathrm{kg}$ for ages $0.5-<2$ years, and 60.9 \pm 18.0 and $77.6 \pm 20.3 \mathrm{~mL} / \mathrm{h} / \mathrm{kg}$ for ages $2-<5$ years, re spectively. In the female patients, the theophylline clearances estimated within 48 hours and at more than 60 hours were $50.1+14.2$ and $55.9 \pm 15.6 \mathrm{~mL} / \mathrm{h} / \mathrm{kg}$ for ages $0.5-<$ 2 years, and $52.2+12.5$ and $70.3 \pm 21.7 \mathrm{~mL} / \mathrm{h} / \mathrm{kg}$ for ages 2 $-<5$ years, respectively.

At ages $0.5-<2$ years, the theophylline clearance estimated at more than 60 hours was higher than that within 48 hours, by $7.5 \%$ in males and $11.7 \%$ in females, but these differences were insignificant. At ages $2-<5$ years, the the ophylline clearance estimated at more than 60 hours was significantly higher than that within 48 hours, by $27.4 \%(p<$ $0.01)$ in males and $34.7 \%(p<0.05)$ in females, respectively.

As for the intra patient variability, individual theophylline clearance estimated at more than 60 hours varied from the value obtained within 48 hours by $-4.8 \%$ to $+66.3 \%$, and the mean theophylline clearance estimated at more than 60 hours was increased by $30.8 \%(p<0.001)$ compared to the value within 48 hours (Table 3 ).

\section{Discussion}

In this study, we have shown that theophylline clearance increases with the time of constant aminophylline infusion in the asthmatic acute phase in Japanese children under 5 years old, although no statistically significant relationship was observed in children aged $0.5-<2$ years. In previous studies, variations in theophylline clearance with time during the course of several months have been reported in chronic childhood asthma ${ }^{15-17)}$. However, the available data concerning the variations in theophylline clearance during the course of a few days in the asthmatic acute phase in children are limited to the report of Kubo et $a l^{9}$. They reported that individual theophylline clearances estimated at 48 hours varied from $-0.4 \%$ to $+57.6 \%$ (the mean theophylline clearance increased by $20.7 \%$ ) at 72 hours after the initiation of a constant aminophylline infusion. In our study, individual theophylline clearances estimated from plasma samples obtained more than 60 hours after the initiation of a constant-rate aminophylline infusion varied from the values estimated from plasma samples obtained within 48 hours after the initiation of the infusion by $-4.8 \%$ to $+66.3 \%$, and the the ophylline clearances estimated at more than 60 hours were $27.4 \%$ higher in males and $34.7 \%$ higher in females at ages $2-<5$ years than those at within 48 hours, respectively, after the initiation of constant aminophylline infusion. The increases in theophylline clearance in children under 5 years old in our study were comparable to the increases in theophylline clearance found in children aged 4 to 13 years in the report of Kubo et $a l^{9}$.

Theophylline clearance is affected by physiologic, pathogenic, and drug related factors. Therefore, it is important to investigate the effects of these factors on theophylline clearance. In this study, insignificant differences in physiological factors were seen between groups of same gender and same age patients. We excluded the data of patients who had complications and/or used drugs reported to affect theophylline clearance. Treatments with prednisolone, oxygen supply, or terbutaline were reported to have no effect on theophylline clearance in our previous study ${ }^{8}$.

The causes and/or mechanisms of the increased theophylline clearance observed during a course of aminophylline infusion lasting over 60 hours have not been studied in children. It has been reported that dehydration, hypoxia and/or acidosis may reduce theophylline clearance in children with acute severe asthma ${ }^{915}$. In our study, no subjects showed severe airway disorders such as respiratory failure, and Kubo et al ${ }^{9)}$ ruled out the possibility that improvements of these conditions in the asthmatic acute phase were related to the increase in theophylline clearance. However, the patients

Table 3 . Infusion times and theophylline clearances consecutively estimated after the initiation of a constant-rate aminophylline infusion.

\begin{tabular}{|c|c|c|c|c|c|c|c|c|c|}
\hline \multirow[t]{2}{*}{ Patient } & \multirow[t]{2}{*}{$\begin{array}{c}\text { Age } \\
\text { (years) }\end{array}$} & \multirow[t]{2}{*}{ Gender } & \multirow[t]{2}{*}{$\begin{array}{l}\text { Weight } \\
(\mathrm{kg})\end{array}$} & \multirow{2}{*}{$\begin{array}{c}\text { Duration of } \\
\text { hospital stays } \\
\text { (d) }\end{array}$} & \multirow[t]{2}{*}{$\begin{array}{l}\text { Infusion rate of } \\
\text { theophylline }(\mathrm{mg} / \mathrm{h} / \mathrm{kg})\end{array}$} & \multicolumn{2}{|c|}{$\begin{array}{l}\text { Infusion time after the start of } \\
\text { constant-rate aminophylline }(\mathrm{h})\end{array}$} & \multicolumn{2}{|c|}{$\begin{array}{l}\text { Theophylline clearance } \\
\qquad(\mathrm{mL} / \mathrm{h} / \mathrm{kg})\end{array}$} \\
\hline & & & & & & within $48 \mathrm{~h}$ & more than $60 \mathrm{~h}$ & within $48 \mathrm{~h}$ & at more than $60 \mathrm{~h}$ \\
\hline 1 & 1.0 & M & 9.9 & 8 & 0.53 & 46.0 & 141.5 & 61.3 & 71.4 \\
\hline 2 & 1.9 & M & 10.0 & 8 & 0.60 & 20.5 & 68.5 & 60.0 & 76.9 \\
\hline 3 & 2.0 & $\mathrm{~F}$ & 11.0 & 7 & 0.48 & 18.5 & 67.0 & 49.1 & 58.7 \\
\hline 4 & 2.0 & F & 13.2 & 9 & 0.51 & 22.0 & 119.0 & 36.7 & 48.8 \\
\hline 5 & 2.2 & M & 11.6 & 7 & 0.60 & 33.0 & 129.0 & 58.1 & 78.0 \\
\hline 6 & 2.9 & M & 12.6 & 5 & 0.58 & 31.5 & 79.0 & 50.1 & 68.4 \\
\hline 7 & 3.2 & M & 15.0 & 7 & 0.53 & 19.0 & 114.5 & 65.5 & 103.4 \\
\hline 8 & 3.7 & $\mathrm{~F}$ & 15.8 & 8 & 0.62 & 41.5 & 89.0 & 45.2 & 75.1 \\
\hline 9 & 3.8 & $\mathrm{~F}$ & 14.4 & 10 & 0.42 & 21.5 & 69.5 & 40.0 & 50.6 \\
\hline 10 & 4.3 & M & 18.2 & 8 & 0.68 & 16.5 & 136.5 & 64.9 & 61.7 \\
\hline 11 & 4.8 & M & 17.6 & 6 & 0.61 & 30.5 & 102.0 & 67.3 & 89.1 \\
\hline \multicolumn{2}{|c|}{ mean \pm S.D. } & & & $7.5 \pm 1.4$ & $0.56 \pm 0.07$ & $27.3 \pm 9.9$ & $101.4 \pm 28.3$ & $54.4 \pm 10.7$ & $71.1 \pm 16.2^{*}$ \\
\hline
\end{tabular}


who revealed theophylline clearance estimated at more than 60 hours had showed the tendency of improvement of airway obstruction and the withdrawal of additional medica tions such as prednisolone and/or oxygen supply, compared with the patients who revealed theophylline clearance estimated within 48 hours in our study. Odajima investigated the effect of an attack of bronchial asthma on theophylline me tabolism in 33 Japanese asthmatic children from 4 to 16 years old and demonstrated that theophylline clearance was $57.4 \pm$ $20.9 \mathrm{~mL} / \mathrm{h} / \mathrm{kg}$ during an attack, while it was 78.3 \pm 31.0 $\mathrm{mL} / \mathrm{h} / \mathrm{kg}$ during a phase of remission ${ }^{18}$. The changes in the ophylline clearance found in his study were comparable to the increases in theophylline clearance observed in our present study. Therefore, the increased theophylline clearance might be explained by the recovery of patient's general condition due to the concurrence of improved dehydration, hypoxia, and acidosis.

In conclusion, our findings suggested that the theophylline clearance estimated at more than 60 hours after the initiation of a constant aminophylline infusion would not be safely applicable to adjust the next initial dose of aminophylline in the asthmatic acute phase in children. Recently, the prescription frequency of theophylline to pediatric patients has decreased because of concerns about the risks of serious adverse effects ${ }^{7}$. Pediatricians and pharmacists should be aware that theophylline clearance might increase during the course of constant aminophylline infusion.

\section{References}

1) M. Y ung, M. South, Randomized controlled trial of aminophylline for severe acute asthma, Arch. Dis. Child ., 79 , 405 -410 (1998).

2) R. M. Ream, L. L. Loftis, G. M. Albers, B. A. Becker, R. E. Lynch, R. B. Mink, Efficacy of IV theophylline in children with severe status asthmaticus, Chest, 119 , 1480-1488 (2001).

3) G. Roberts, D. Newsom, K. Gomez, Intravenous salbutamol bolus compared with an aminophylline infusion in children with severe asthma: a randomized controlled trial, Thorax, 58 , 306-310 (2003).

4) K. Blake, A. K. Kamada "' Textbook Of Therapeutics: Drug A nd Disease Management”, 6 th ed., ed. by E. T. Herfindal, D.R. Gourley, Williams \& Wilkins, Baltimore, $1996, \mathrm{pp}$. 662-667.

5) N. A . Minton, J. A. Henry, A cute and chronic human toxic- ity of theophylline, Human Exp. Toxicol., 15, 471-481 (1996).

6) A. Ohnishi, A review of clinical use of theophylline in acute asthma: factors influencing kinetic disposition and drug interactions, Methods Find Exp. Clin. Pharmacol., 22 , 253258 (2000).

7) T. H. Self, C. C. Chafin, J. E. Soberman, Effect of disease states on theophylline serum concentrations: are we still vigilant? , Am. J. Med. Sci., 319 , 177-182 (2000).

8) T. Igarashi, S. Iwakawa, Effect of gender on theophylline clearance in the asthmatic acute phase in Japanese pediatric patients, Biol. Pharm. Bull., 32 , 304-307 (2009).

9) M. Kubo, Y. Odajima, T. Ishizaki, S. Kanagawa, M. Y ama guchi, T. Nagai, Intraindividual changes in theophylline clearance during constant aminophylline infusion in children with acute asthma, J. Pediatr., 108 , 1011-1015 (1986).

10) Japanese Pediatric Allergic Society "“ Japanese Pediatric Guideline for The Treatment and Management of Asthma 2005", ed. by A. Morikawa, S. Nisima, Kyowa kikaku, Inc., Tokyo, 2005, pp. 76-82.

11) T. Toba, T. Kurosaki, F. Ohta, K. Tamai, H. Ikegami, Y. Saitoh, Y. Matsuya, K. Makino, T. A sai, Decreased theophylline clearance in children with acute asthma with concurrent febrile respiratory infection, Arerugi, 43, 113-119 (1994).

12) M. Rowland, T. N. Tozer ", Clinical Pharmacokinetics: Concepts and A pplications", 2 th ed., ed. by M. Rowland, T. N. Tozer, Lea \& Febiger, Philadel phia, 1989 , pp. 63-77.

13) M. Weinberger, L. Hendeles, Theophylline in asthma, $N$. Engl. J. Med., 334 , 1380-1388 (1996).

14) Package Insert of the reagent pack, TDX-Theophylline assay system, A bbott Laboratories, 2003.

15) J. D. A rnold, G. N. Hill, L. N. Sansom, A comparison of the pharmacokinetics of theophylline in asthmatic children in the acute episode and in remission, Eur. J. Clin. Pharmacol., 20 , 443-447 (1981).

16) P. Leung, A. Kalisker, T. D. Bell, V ariation in theophylline clearance rate with time in chronic childhood asthma, $\mathrm{J}$. Allergy Clin. Immunol., 59, 440-444 (1977).

17) P. D. Walson, R. C. Strunk, L. M. Taussig, Intrapatient variability in theophylline kinetics, J. Pediatr., 91 , 321-324 (1977).

18) Y. Odajima, Examination of theophylline pharmacokinetics during an attack of bronchial asthma in children, Arerugi, 41 , 22-28 (1992). 